\title{
Role of Hormonal Manipulations in Delaying the Progression of Lymphangioleiomyomatosis (LAM): A 16-Years Follow-Up Report after Oophorectomy
}

Niroshan Thiruchelvam ${ }^{1 *}$, Vidhya Karivedu², Farayi Mbuvah², Gaurav Kistangari ${ }^{3}$ and Basma Ricaurte ${ }^{1}$

${ }^{1}$ Department of Pulmonary Medicine, Respiratory Institute, Cleveland Clinic, Cleveland, $\mathrm{OH}, \mathrm{USA}$

${ }^{2}$ Department of Internal Medicine, Fairview Hospital, Cleveland, USA

${ }^{3}$ Department of Hospital Medicine, Cleveland Clinic, Cleveland, USA

\section{Introduction}

Lymphangioleiomyomatosis (LAM) is an uncommon cystic lung disease caused by infiltration of the lung with smooth muscle cells that arise from an unknown source, spread via blood and lymphatics, and contain growth-activating mutations in tuberous sclerosis genes $[1,2]$. LAM occurs in patients with tuberous sclerosis complex (TSCLAM) and in a "sporadic" form in patients who do not have tuberous sclerosis (S-LAM) [3]. It is a slowly progressive lung disease that leads to respiratory failure over one to two decades. It is exclusively seen in women and is characterized by progressive proliferation of smooth muscle-like cells (LAM cells) in lung parenchyma and causes cystic destruction, chylous pleural effusions and recurrent pnuemothoraxes. LAM has historically been considered an estrogen dependent tumor and was treated with hormonal manipulation strategies such as antiestrogens, antiprogesterones and oophorectomy. Current insights into the pathophysiology of LAM have provided new treatment drugs such as sirolimus, a mTOR inhibitor, that is effective in stabilizing lung function. Since the advent of novel therapies, hormonal manipulation strategies have become less popular. We describe a case of LAM in a young woman who underwent oophorectomy and was followed closely for 16 years without worsening of her lung function.

\section{Presentation}

A 49-year-old female was referred to our institution in 1996 for recurrent pneumothoraces. Computed tomography of the chest demonstrated (Figure 1) numerous cystic lesions uniformly scattered throughout the lung. A subsequent lung biopsy confirmed the histologic diagnosis of S-LAM (Figure 2). Pulmonary function tests (PFTs) showed forced expiratory volume in 1 second (FEV1) of $2.68 \mathrm{~L}$, forced volume vital capacity (FVC) of $4.56 \mathrm{~L}$, total lung capacity (TLC) of $6.18 \mathrm{~L}$ and a diffusing capacity (DLCO) of 21.3. She had a $15 \mathrm{yr}$. history of smoking and her other comorbidities included asthma and uterine leiomyoma. She was subsequently treated with hysterectomy and oophorectomy. Sixteen years following the surgery, she remained asymptomatic and serial PFTs done over the same time period interestingly did not show progressive worsening of her lung function. Her most recent PFTs in 2013 showed FEV1 of $2.25 \mathrm{~L}$. She did not receive any targeted therapy and is not requiring supplemental oxygen at rest or during exertion.

\section{Discussion}

LAM is a rare multisystem disease of women that targets the lung. There are several features of LAM that suggests its estrogen dependency such as its propensity to affect females, occurrence before menopause, and worsening respiratory function during pregnancy [4]. Estrogen and progesterone receptors expression is seen in LAM cells $[5,6]$. In patients with LAM, FEV1 declines at rates that vary from 50 to $250 \mathrm{ml} /$ yr [7]. Lung function decline is more rapid in patients with S-LAM. Patient did not show significant lung function declined which likely due to oophorectomy. Estradiol is known to play an important role in the

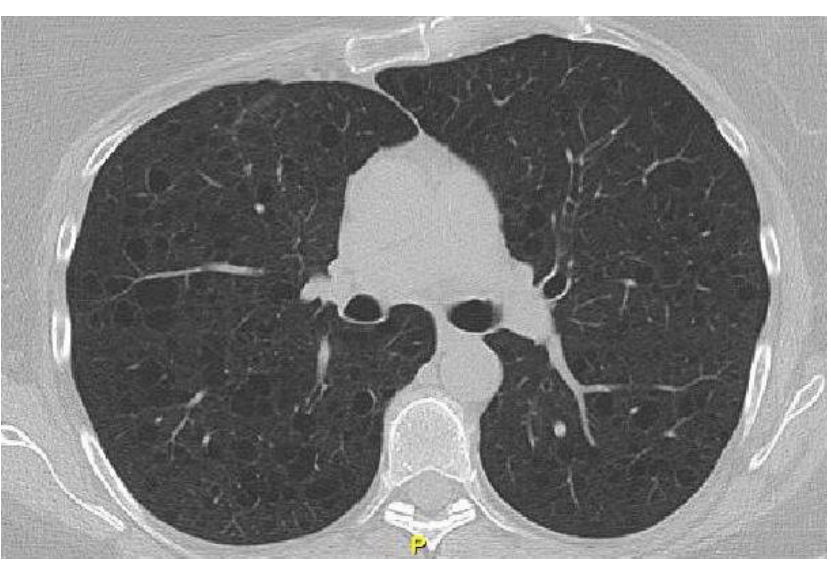

Figure 1: CT chest demonstrated numerous cystic lesions uniformly scattered throughout the lung.

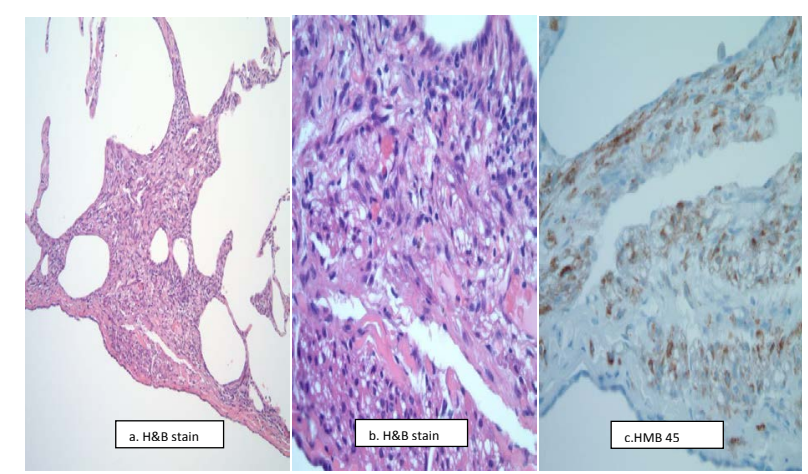

Figure 2 a,b,c: Histology of lung biopsy showed proliferation of immature smooth muscle associated with lymphatic spaces. These cells are positive for immunohistochemical markers actin desmin and HMB 45. These findings confirmed the histologic diagnosis of LAM.

*Corresponding author: Niroshan Thiruchelvam, MD, Department of Pulmonary Medicine, Respiratory Institute, Cleveland Clinic, Cleveland, OH, USA, Tel: (216) 904 1965; E-mail: thirucn@ccf.org

Received November 23, 2015; Accepted December 29, 2015; Published December 31, 2015

Citation:Thiruchelvam N, Karivedu V, Mbuvah F, Kistangari G, Ricaurte B (2015) Role of Hormonal Manipulations in Delaying the Progression of Lymphangioleiomyomatosis (LAM): A 16-Years Follow-Up Report after Oophorectomy. J Clin Respir Dis Care 1: 103. doi: 10.4172/ JCRDC.1000103

Copyright: (c) 2015 Thiruchelvam N, et al. This is an open-access article distributed under the terms of the Creative Commons Attribution License, which permits unrestricted use, distribution, and reproduction in any medium, provided the original author and source are credited. 
Citation: Thiruchelvam N, Karivedu V, Mbuvah F, Kistangari G, Ricaurte B (2015) Role of Hormonal Manipulations in Delaying the Progression of Lymphangioleiomyomatosis (LAM): A 16-Years Follow-Up Report after Oophorectomy. J Clin Respir Dis Care 1: 103. doi: 10.4172/ JCRDC.1000103

pathophysiology of LAM, and further studies are required to identify those patients who may just benefit from hormonal blockade therapy. They were preclinical studies shown promising results with anti-estrogen therapy [4]. Although novel agents have shown promise in controlling symptoms [8], they are associated with drug toxicity and development of resistance, and never been tested in randomized control trails (RCTs) in direct comparison with hormonal manipulation. In this report we hope to demonstrate that hormonal manipulation might still be beneficial in certain subset of patients with LAM.

\section{References}

1. Henske EP, McCormack FX (2012) Lymphangioleiomyomatosis - a wolf in sheep's clothing. J Clin Invest 22: 3807-3816.

2. McCormack FX, Travis WD, Colby TV, Henske EP, Moss J (2012) Lymphangioleiomyomatosis: calling it what it is: a low-grade, destructive, metastasizing neoplasm. Am J Respir Crit Care Med 186: 1210-1212.
3. Crino PB, Nathanson KL, Henske EP (2006) The tuberous sclerosis complex. $N$ Engl J Med 355: 1345-1356.

4. Li C, Zhou X, Sun Y, Zhang E, Mancini JD, et al (2013) Faslodex inhibits estradiol-induced extracellular matrix dynamics and lung metastasis in a model of lymphangioleiomyomatosis. AmJ Respir Cell Mol Biol 49: 135-142.

5. Baldi BG, Medeiros Junior P, Pimenta SP, Lopes RI, et al. (2011) Evolution of pulmonary function after treatment with goserelin in patients with lymphangioleiomyomatosis. J Bras Pneumol 37: 375-379.

6. Yu JJ, Robb VA, Morrison TA, Ariazi EA, Karbowniczek M, et al. (2009) Estrogen promotes the survival and pulmonary metastasis of tuberin-null cells. Proc Natl Acad Sci 106: 2635-2640.

7. Taveira-DaSilva AM, Stylianou MP, Hedin CJ, Hathaway O, Moss J (2004) Decline in lung function in patients with lymphangioleiomyomatosis treated with or without progesterone. Chest 126: 1867-1874.

8. McCormack FX, Inoue Y, Moss J, Singer LG, Strange C, et al. (2011) Efficacy and safety of sirolimus in lymphangioleiomyomatosis. N Engl J Me 364: 15951606. 